
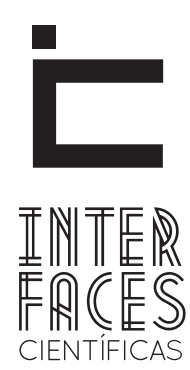

DIREITO

ISSN IMPRESSO 2316-3321

E - ISSN 2316-381X

DOI - 10.17564/2316-381X.2018v6n2p97-112

SEÇ̃̃oll- DIRETTOS FUNDAMENTAIS INDIVIDUAIS E COLETIVOS

\title{
DISCURSOS SOBRE LAICIDADE: TEORIAS, PRAGMATISMO E POSSIBILIDADES
}

\author{
SECULARISM SPEECHES: THEORIES, PRAGMATISM AND POSSIBILITIES
}

DISCURSOS SOBRE LAICIDAD: TEORÍAS, PRAGMATISMO Y POSIBILIDADES.

\section{RESUMO}

0 presente artigo objetiva discutir um conteúdo material para a laicidade a partir de pressupostos teóricos interdisciplinares em uma perspectiva dogmática pós-positivista, com vistas à delimitação de relações possíveis entre o conteúdo do princípio e a elaboração da cidadania. A pesquisa se caracteriza como jurídico-dogmática. Os dados, de natureza secundária bibliográficos e documentais, serão analisados a partir dos métodos sistemático e sociológico, tendo em vista a necessidade de se investigar o alcance da prática hermenêutica pós-positivista e o seu impacto na produção da realidade social. Como resultado das discussões propostas deve-se considerar os pressu- postos da laicidade estrita, quais sejam: liberdade de consciência, igualdade entre cidadãos críticos e neutralidade do Estado, como instrumento viabilizador para a materialidade da laicidade formal e dos diversos direitos que se encontram amparados pela garantia constitucional, uma inflexão necessária à práxis hermenêutica nacional.

\section{PALAVRAS-CHAVE}

Laicidade, Pós-positivismo, Cidadania-crítica, Neoconstitucionalismo, Agir comunicativo. 


\section{ABSTRACT}

This article aims to discuss a material content for secularity from interdisciplinary theoretical assumptions in a post-positivist dogmatic perspective, in order to delineate the possible relations between the content of the principle and the elaboration of citizenship. The research is characterized as legal-dogmatic. The bibliographic and documentary secondary data will be analyzed from the systematic and sociological methods, considering the need to investigate the reach of the post-positivist hermeneutic practice and its impact on the production of social reality. As a result of the proposed discussions, the assumptions of strict secularity,

\section{RESUMEN}

El presente artículo objetiva discutir un contenido material para la laicidad a partir de presupuestos teóricos interdisciplinares en una perspectiva dogmática pospositivista, con vistas a la delimitación de relaciones posibles entre el contenido del principio y la elaboración de la ciudadanía. La investigación se caracteriza como jurídico-dogmática. Los datos, de naturaleza secundaria bibliográfica y documental, serán analizados a partir de los métodos sistemático y sociológico, teniendo en vista la necesidad de investigar el alcance de la práctica hermenéutica pospositivista y su impacto en la producción de la realidad social. Como resultado de las discusiones propuestas such as: freedom of conscience, equality between critical citizens and neutrality of the State, should be considered as an instrument for making the materiality of formal secularity feasible and the many rights that are protected by the constitutional guarantee, a necessary inflection for national hermeneutical praxis.

\section{KEYWORDS}

Secularism. Post-positivism. Citizenship-criticism. Neo-constitutionalism. Communicative action. se deben considerar los supuestos de la laicidad estricta, que son: libertad de conciencia, igualdad entre ciudadanos críticos y neutralidad del Estado, como instrumento viable para la materialidad de la laicidad formal y de los diversos derechos que se hallan amparados por la garantía constitucional, una inflexión necesaria para la praxis hermenéutica nacional.

\section{PALABRAS CLAVE}

Laicidad, Pospositivismo, Ciudadanía crítica, Neoconstitucionalismo, Acción comunicativa. 


\section{INTRODUÇÃ̃O}

Os ideais de liberdade, igualdade e pluralismo são axiomas informadores do ordenamento jurídico brasileiro, consagrados constitucionalmente e amplamente discutidos pela doutrina e jurisprudência. No entanto, a despeito desta realidade formal, profundas são as diferenças sociais, historicamente constituídas e de difícil enfrentamento, nos mais diversos campos. Sendo, nestes contextos, as discrepâncias específicas relacionadas à experiência das liberdades de consciência, pensamento, crença e culto - além e outras aportadas em questões culturais -, diretamente ligadas ao conteúdo principiológico da laicidade. Isto posto, objetiva o presente artigo discutir um conteúdo material para a laicidade a partir de pressupostos teóricos interdisciplinares em uma perspectiva dogmática pós-positivista, com vistas à delimitação de relações possíveis entre o conteúdo do princípio e a elaboração da cidadania.

A pesquisa se caracteriza em seu aspecto teórico-metodológico como jurídico-dogmática, uma vez que a análise se circunscreve a um fenômeno estritamente (GUSTIN; DIAS, 2015, p. 27). Os dados, de natureza secundária, bibliográficos e documentais, serão analisados a partir dos métodos sistemático e sociológico, tendo em vista a necessidade de se investigar o alcance da prática hermenêutica pós-positivista e o seu impacto na produção da realidade social (UNDURRAGA, 2002, p. 30).

0 trabalho se inicia com uma abordagem sobre os novos parâmetros da produção hermenêutica pós-positivista, para em seguida enfrentar as questões teóricas da laicidade, sendo neste momento, apresentados os pressupostos da laicidade a partir da perspectiva teórica de Henri Pena-Ruiz. Por fim, são estabelecidas relações entre tais premissas e a elaboração da cidadania-critica, por meio de um diálogo com a teoria do agir comunicativo de Jürgen Habermas.

\section{PÓS-POSITIVISMO, HERMENÊUTICA CONSTITUCIONAL E INTERDISCIPLINARIDADE}

Nas lições de Barroso (2015, p. 263), “o Direito é uma invenção humana [...], concebido como técnica de solução de conflitos e instrumento de pacificação", que se perfaz no intervalo entre a abstração das normas juridicamente postas e a concretude de sua aplicação, quando os atritos sociais demandam o reestabelecimento da ordem.

Tal reestabelecimento, implica, necessariamente a incidência do direito, e este, a seu turno, enquanto trabalho precípuo do jurista é atividade indissociável da prática interpretativa, uma vez que "a interpretação jurídica consiste na atividade de revelar ou atribuir sentido a textos ou outros elementos normativos, notadamente para o fim de solucionar problemas" (BARROSO, 2015, p. 304). A questão que se coloca diz respeito aos limites teóricos e práticos dessa produção hermenêutica e as implicações do interprete e aplicador do direito na produção social da realidade.

Enfrentando os limites da hermenêuticajurídica, Barroso (2015, p. 309-312) discorre acerca das correntes de pensamento veiculadas na ciência do Direito, desde momentos passados até os dias e práxis atuais:

\footnotetext{
Ao longo dos últimos dois séculos, uma multiplicidade de teorias jurídicas foram concebidas e propagadas [...], no entanto, por necessidade de encadeamento do raciocínio e por imperativo didático, percorre-se brevemente o tema, agrupando-se as diferentes teorias ou metodologias em quatro grandes categorias: (i) o formalismo, (ii) a reação antiformalista, (iii) o positivismo e (iv) a volta dos valores [...] o formalismo jurídico tem como marca essencial uma concepção mecanicista do Direito, pela qual a interpretação jurídica seria uma atividade acrítica de subsunção dos fatos à norma [...] pregava o apego à literalidade do texto legal e à intenção do legislador [...] a reação antiformalista [...] defendeu que o Direito deve servir aos fins sociais, antes que aos conceitos e às formas (teve como características) a reação à crença de que o Direito poderia ser encontrado integralmente no texto da lei e nos precedentes judiciais, a rejeição da tese de que a função judicial seria meramente declaratória, para
} 
reconhecer, ao contrário, que em diversas situações o juiz desempenha um papel criativo, e a compreensão da importância dos fatos sociais, das ciências sociais e da necessidade de interpretar o direito de acordo com a evolução da sociedade [...] o positivismo jurídico apresenta uma característica essencial, que une fases e autores bem diversos: a separação entre o Direito e Moral, entre a lei humana e o direito natural, negando a existência de um direito natural que subordine a legislação [...] em sua pretensão de criar uma ciência do Direito objetiva eneutra, o positivismo compartiIhou muitas das premissas teóricas do formalismo [...] a volta dos valores é a marca do pensamento jurídico que se desenvolve a partir da segunda metade do século XX,foi, em grande parte, consequência da crise moral do positivismo jurídico e da supremacia da lei, após o holocausto e a barbárie totalitária do fascismo e do nazismo [...] a volta dos valores está no centro da discussão metodológica contemporânea e do pensamento pós-positivista.

No bojo das discussões pós-positivistas, entende Barroso (2015, p. 314) estar no núcleo da atuação deste hermeneuta jurídico, a busca pela solução de conflitos, não dissociada de um reconhecimento acerca da parte que the cabe na elaboração social, sobretudo no tocante à "pretensão de conformar a realidade - o ser - ao dever-ser constitucional", isto é, uma práxis que possibilite um encontro entre os preceitos normativos axiomáticos dos textos constitucionais e a realidade social, por isso, como afirma o autor, a hermenêutica pós-positivista se circunscreve num cenário marcado pela

[...] complexidade da vida contemporânea, tanto no espaço público como no espaço privado; o pluralismo de visões, valores e interesses que marcam a sociedade atual; as demandas por justiça e pela preservação e promoção dos direitos fundamentais. (BARROSO, 2015, p. 299-300).

Portanto, de modo que, o interprete, não podendo negligenciar estas demandas, deve incorporar em sua práxis os conteúdos suficientes ao atendimento de tais urgências.

Neste diapasão, o conhecimento jurídico demanda uma perspectiva crítica e interdisciplinar, isto porque "o interprete deve buscar a justiça, ainda quando não a encontre na lei (isto é), o estudo do sistema normativo (dogmáticajurídica) não pode insular-se da realidade e das bases de legitimidade que devem inspirá-lo e possibilitar a sua própria crítica”. Sendo neste interim que se evidencia de uma necessária "interdiscipliridade, que colha elementos em outras áreas do saber", com vistas a uma produção hermenêutica que, efetivamente, propicie as aproximações demandadas na contemporaneidade (BARROSO, 2015, p. 265).

\section{AS TEORIAS FRANCESAS PARA LAICIDADE}

Tradicionalmente, a laicidade é conceituada como sendo um princípio de separação, entre os interesses religiosos e a atuação estatal, dirigido à consagração de liberdades e igualdade (SARMENTO, 2008). Um regime social de convivência (LOREA, 2008), cujas instituições políticas se encontram legitimadas pela soberania popular e não mais em elementos religiosos, como nos regimes que precederam a modernidade (BLANCARTE, 2008) e, como elemento de integração social (ORO, 2008). Construções relevantes, indispensáveis a apreensão do fenômeno, mas que aportam suas premissas na juridicidade, na formalidade do discurso jurídico.

É preciso que o fenômeno da laicidade seja abordado tanto em seu aspecto formal, quanto em sua faceta material, isto porque, um princípio normativo que se proponhaa firmar um regime de convívio e integração social não pode ser analisado dissociado da realidade social, dos antecedentes sócio-históricos e da percepção dos sujeitos que são atravessadas pelas questões que do fenômeno se desdobram. Nisto, enquanto o art. 19, inciso I, da Carta Magna Brasileira de 1988, informa os limites da laicidade formal, a materialidade do fenômeno deve ser delimitada e mensurada a partir de fatores outros, discutidos para além da abstratividade dos códigos.

De acordo com a historiadora francesa Valentine Zuber (2010, p. 161), a laicidade é um fenômeno polimorfo, cuja complexidade se desdobra em facetas históricas, sociológicas e jurídicas, como produto das "relações entre as diferentes religiões, mas também 
nas relações existentes entre religião(ões), Estado(s) e sociedade civil”. Como pontua a pesquisadora, na França, espaço onde a laicidade encontrou particular processo de concretização, três grandes correntes teóricas podem ser identificadas. Na primeira delas, a laicidade é compreendida enquanto um fenômeno histórico-jurídico cuja materialidade se deu exclusivamente no território francês. Nesta corrente, capitaneada na contemporaneidade pelo filósofo Henri Pena-Ruiz, é apresentado pressupostos para uma mensuração da laicidade numa perspectiva de concretude social.

A segunda corrente, ainda de acordo com Zuber (2010), compreende a laicidade como uma realização da modernidade, portanto experimentada em todos os países do ocidente. Pensadores como Marcel Gauchet, figuram essa corrente. Uma terceira corrente é apresentada, compreendendo a laicidade como uma aspiração humana, um fenômeno jurídico inevitável à marcha democrática, portanto, não circunscrito ao ocidente, estando inserido nos anseios de povos orientais, v.g., quando lutas pelo reconhecimento de direitos e garantias, próprias à perspectiva democrática, passam a ocupar os pensamentos e ações dos grupos sociais. Neste sentido, vozes como a de Mohamed-ChérifFerjani representam esta corrente.

Zuber (2010, p. 179-180), ao enfrentar as distancias e aproximações entre os elementos das três correntes, pontua que, o estudo sobre o fenômeno da laicidade:

\begin{abstract}
Não pode certamente abstrair-se destas (divergências e congruências teóricas) e deve mesmo dar-se conta disso, o mais honestamente possível. Mas eu continuo persuadida de que deve considerá-los como elementos de reflexão necessários, mas não suficientes a uma apreensão fina e distanciada da realidade das laicidades.
\end{abstract}

Deste modo, no intento de propiciar aprofundamentos necessários aos discursos nacionais acerca da laicidade, dedicar-se-á o atual estudo a discutir a laicidade, conforme discorre a primeira corrente, enquanto "um gesto especificamente francês". Levando em conta, como destaca Zuber (2010), os pressupostos para mensuração do fenômeno laico, extraídos pelos teóricos da experiência histórico-social francesa.

\subsection{LIMITES TEÓRICOS PARA UMA LAICIDADE ESTRITA}

De acordo a primeira corrente teórica francesa, a laicidade seria um fenômeno necessariamente social, identificado na experiência histórica de um grupo, para apenas, em seguida, ser percebido como conteúdo normativo. O ideal laico, segundo Henri Pena-Ruiz (2003b, p. 71), deve ser percebido não apenas como um referencial, um princípio fundador, mas antes como:

Direito político fundamental. Abrangendo um ideal universalista da organização da cidade (Estado) e do sistema jurídico que ao mesmo tempo é baseado nele e por ele se realiza. A palavra que informa o princípio, a laicidade refere-se à unidade do povo, grego laos (povo único), e está baseada em três elementos indissociáveis: (1) a liberdade de consciência, (2) igualdade de todos os cidadãos, independentemente das suas crenças espirituais, sexo ou origem, e que se refere ao (3) interesse geral, a busca pelo bem comum a todos, como única razão de ser do Estado.

Em sua argumentação, Pena-Ruiz (2003b, p. 9) sustenta que não há que se falar em laicidade sem que exista, materialmente, a experiência de:

Liberdade de consciência e de igualdade de direitos. (De modo que) a liberdade de consciência exclui qualquer restrição religiosa ou ideológica. Igualdade de direitos é incompatível com o valorização privilegiada de uma crença ou ateísmo (vedação à existência de crenças). Poder público, comum a todos, res publica, será, portanto, no nível confessional neutro: neutro, que em latim significa exatamente: nem um nem o outro.

A mera previsão normativa, dissociada da materialidade social é uma coisa distinta daquilo que se deve conceber como laicidade. Portanto, para que se possa afirmar um determinado Estado como laico, é necessário que se verifique, a existência dos três pressupostos da laicidade, quais sejam: a liberdade de consciência, a igualdade entre os cidadãos e a neutralidade estatal, enquanto posicionamento equidistante entre todos os cultos e não-cultos, com vistas à viabilização dos dois pressupostos anteriores.

Aquele Estado que apenas apresenta uma previsão normativa laica, mas não possui uma correlata ex- 
periência histórica e social destes pressupostos, não pode afirmar-se materialmente laico, configurando-se como outro formato jurídico, uma quase-laicidade, como defendem alguns autores (CATROGA, 2010; RANQUETAT JR., 2008). Neste intervalo conceitual percebido entre as experiências materiais de laicidade e aquelas meramente formais, é que emerge o conceito de laicidade estrita, defendido pela primeira corrente, como sendo aquela experiência que, para além dos postulados jurídicos formais, apresenta, concomitantemente, correspondentes sócio-históricos de luta e reconhecimento de direitos de consciência e igualdade, dirigidos à materialização da separação entre interesses do Estado e das religiões.

\subsubsection{PRESSUPOSTOS DA LAICIDADE}

Na perspectiva de Pena-Ruiz (1999, p. 24): a laicidade se configura enquanto "un príncipe d'unionqui, pour n'exclurepersonne, stipulesimultanémentlaplustotale liberte de conscience, définitl'originalité de l'idéelaiqque", a saber, um princípio de união, social e juridicamente instrumentalizável, que ao estabelecer a máxima liberdade de consciência, serve para balizar as relações em sociedade; a impossibilidade, de qualquer espécie, de exclusão ou discriminação em razão do pensamento religioso, viabilizando assim o convívio na medida em que todos passam a ocupar posições isonômicas diante deste Estado.

O formato sustentado pela primeira corrente, de separação laica ou laicidade estrita, mensurável a partir dos três pressupostos, pode ser identificado em uma dada sociedade, por meio de dois critérios. Num primeiro momento, quando inexistentes pactos, acordos ou outra manifestação jurídica que localize determinado culto em posição de privilégio ou superioridade em relação aos demais e aos cidadãos e, em um segundo momento, pela apreensão dos três pressupostos inerentes a uma sociedade laica (PENA-RUIZ, 2003b, p. 241-242).

Desta forma, faz-se necessária uma abordagem mais detalhada sobre tais pressupostos sociais, históricos e jurídicos que informam a laicidade estrita.

\subsubsection{LIBERDADE DE CONSCIÊNCIA}

Para que se possam discutir os limites jurídicos de uma liberdade de consciência é preciso, antes, que reste claro o conteúdo deste conceito de consciência, sendo necessário para tanto a utilização de teorias elaboradas por campos outros do conhecimento, como a sociologia e a psicologia social.

Ao desenvolver sua teoria sobre a consciência, Alexis Nikolaevich Leontiev utiliza como pressuposto teórico a ontogênese humana, ao evidenciar as disparidades entre a atividade psíquica humana e animal.

\begin{abstract}
A passagem à consciência é o início de uma etapa superior ao desenvolvimento psíquico. 0 reflexo consciente, diferentemente do reflexo psíquico próprio do animal, é o reflexo da realidade concreta destacada das relações que existem entre ela e o sujeito, ou seja um reflexo que distingue as propriedades objetivas estáveis da realidade. Na consciência, a imagem da realidade não se confunde com a do vivido do sujeito: o reflexo é como 'presente' ao sujeito. Isto significa que quando tenho consciência de um livro, por exemplo, ou muito simplesmente consciência do meu próprio pensamento a ele respeitante. 0 livro não se confunde na minha consciência com o sentimento que tenho dele, tal como o pensamento deste livro não se confunde com o sentimento que tenho dele. A consciência humana distingue a realidade objetiva do seu reflexo, o que leva a distinguir o mundo das impressões interiores e torna possível com isso o desenvolvimento da observação de si mesmo. (LEONTIEV, 2004, p. 75, grifos nossos).
\end{abstract}

Esta percepção de si, como destaca Leontiev (2004), implica a própria condição de ser humano, sua hominização, disparada por meio do aparecimento e desenvolvimento do trabalho, enquanto atividade própria à condição humana, diferente daquela observada na atividade animal. Isto porque, enquanto os animais agem diretamente para o atendimento de suas necessidades, por meio de ações sempre imediatas, homens e mulheres se dirigem para o atendimento de suas necessidades por meio da elaboração de atividades intermediárias, mediatas, localizadas entre a necessidade e o seu atendimento. Sendo este o conceito mais abrangente de trabalho. 
O psicólogo, citando Marx, esclarece o conceito de trabalho enquanto elemento intermediário:

O trabalho é primeiramente um ato que se passa entre
o homem e a natureza. O homem desempenha aí para
com a natureza o papel de uma potência natural. As
forças de que o seu corpo é dotado, braços c pernas,
cabeça e mãos, ele as põe em movimento a fim de as-
similar as matérias, dando-lhes uma forma útil à sua
vida. Ao mesmo tempo que age por este movimento
sobre a natureza exterior e a modifica, ele modifica a
sua própria natureza também e desenvolve as facul-
dades que nele estão adormecidas. (LEONTIEV, 2004,
p. 80 , grifos nossos).

0 trabalho, assim, enquanto ação transformadora sobre os elementos da natureza para elaboração de instrumentos facilitadores da vida configura-se como elemento capaz de alterar a realidade na qual estão inseridos homens e mulheres e, ao mesmo tempo, efetua também modificação na condição humana, na medida em que passam os indivíduos a elaborarem não apenas os instrumentos, mas a si próprios, no processo tratado como hominização.

O trabalho, como prossegue Leontiev (2004, p. 80), caracteriza-se por dois elementos interdependentes: o fabrico de instrumentos e a necessária condição coletiva, social, destes processos, tendo em vista que, por meio do trabalho, o homem "não entra apenas numa relação determinada com a natureza, mas com outros homens, membros de uma dada sociedade, (sendo) apenas por intermédio desta relação [...] que o homem se encontra em relação com a natureza”.

Pelo trabalho, o intelecto humano cria os instrumentos mediadores para satisfação das suas necessidades, tais instrumentos, úteis à produção material da vida, são então incorporados a pratica social do grupo, por meio de processos de apropriação, forjando a cultura experimentada e esta, por sua vez, viabiliza a historicidade da experiência humana. É, neste sentido, que, destaca Codo (1984, p. 52) ser "o instrumento de trabalho um mediador entre o homem e a sua transcendência, em outras palavras, a sua história”.

0 processo de humanização se perfaz na medida em que, ao acessar os instrumentos socialmente par- tilhados, acessa também a historicidade neles contida e, ao passo em que elabora e utiliza tais instrumentos, numa dinâmica sempre coletiva, elabora também a si mesmo, quando dirige-se à reprodução das condições materiais da vida social (LEONTIEV, 2004, p.80).

Ao discorrer sobre a ontogênese humana, Leontiev (2004) também destaca dois aspectos importantes para a compreensão da consciência em homens e mulheres, o primeiro deles: a habilidade de antecipação de resultados e o segundo: a fragmentariedade das ações. Como pontua o autor, no trabalho coletivo, quando da realização de atividades antes disparadas institivamente, é desenvolvido um elemento finalístico, que por sua vez, projeta o resultado perseguido e é capaz de alterar profundamente a estrutura da atividade entre os humanos. Dito de outra forma, as atividades, quando pensadas e realizadas de maneira coletiva, a partir do fator social, adquire uma intenção final que pode operar na atividade total uma série de pequenas divisões. Ações, que realizadas isoladamente, podem, por vezes, resultar numa visível contradição.

Para ilustrar esse aspecto teórico, é utilizado o exemplo da caça coletiva em que um grupo considera como elemento finalístico a obtenção de alimento, mas divide entre seus integrantes ações com conteúdos distintos, havendo dentre eles, alguns com funções aparentemente contraditórias, como aqueles que afugentam os animais, impelindo-os ao abate e, por conseguinte, ao objetivo coletivo. Desta forma, o indivíduo, na função de batedor, quando espanta a caça, realizando o fragmento da atividade que the cabe, compreende a finalidade de sua ação e a correspondência indireta, mediata, com a finalidade coletiva e, com efeito, com sua finalidade fragmentada (LEONTIEV, 2004, p. 82-83).

Desta forma, assevera Leontiev (2004, p. 85) que, “a decomposição de uma ação supõe que o sujeito que age tem a possibilidade de refletir psiquicamente a relação que existe entre o motivo objetivo da relação e o seu objeto. Senão, a ação é impossível, é vazia de sentido para o sujeito", senda esta capacidade de reflexão, que é essencialmente social, o traço distintivo da consciência humana. 
O indivíduo que atua em sociedade incorpora os instrumentos desenvolvidos pelo grupo com vistas à facilitação da vida, por meio da cultura que o perpassa, e nestas dinâmicas, fragmenta a atividade em ações, que por vezes pode implicar conteúdos contraditórios aos interesses particulares, no entanto, permanece consciente, aquele sujeito que conhece os sentidos de suas ações e sua conexão com as finalidades estabelecidas pelos grupos e seus integrantes, de modo a constituir as razões da fragmentariedade das ações e os sentidos que as orientam e sustentam.

Nestes processos reflexivos de apreensão dos sentidos, os indivíduos constituem saberes sobre si e sobre as posições que ocupam nos grupos, por meio das ações que realizam, por isso se elaboram, quando estão a pensar e repensar suas atividades, numa concretização, tanto do trabalho quanto de si mesmos (LEONTIEV, 2004, p. 91).

Assim, o processo de ontogênese humana, a saber, a dinâmica pela qual se humaniza o indivíduo se dá socialmente, quando por meio do trabalho é incorporada a historicidade dos instrumentos, seus sentidos, finalidades, propiciando ao sujeito a capacidade de elaborar suas ações e a si mesmo, a partir de sua localização no corpo social.

Em idêntica direção, ao enfrentar as questões de consciência e alienação, destaca Silvia T. M. Lane (1984, p. 40) que,

\footnotetext{
[...] o indivíduo sujeito da história é constituído de suas relações sociais e é, ao mesmo tempo, passivo e ativo (determinado e determinante). Ser mais ou menos atuante como sujeito da história depende do grau de autonomia e de iniciativa que ele alcança.
}

Pode-se afirmar, então, que a consciência de si é a capacidade de percepção acerca destes processos constitutivos, sociais, que atravessam o sujeito, de maneira que, aquele indivíduo consciente de si está ciente, necessariamente, de seu pertencimento a uma classe social determinada, de modo que sua consciência, a depender do seu grau de autonomia, se processa, transformando tanto suas ações quanto a ele mesmo. Nesse diapasão, a consciência de si é percebida como processo psicossocial, na medida em que se dá, concomitantemente, na mente do indivíduo e nas relações sociais que lhe são determinantes.

Nisto, a consciência de-si-social é pontualmente a habilidade de perceber-se enquanto produto mediato de uma historicidade que atravessa interações sociais que lhes são imediatas, posicionando o indivíduo, nestes processos, não apenas como sujeito determinado, passivo, mas como determinante, ativo, por meio das transformações que pode fazer ocorrer nas relações sociais das quais participa (LANE, 1984, p. 42).

A autoidentificação no grupo, a saber, o senso de pertença a determinada classe social é manifesta como consciência de classe e informa ao indivíduo as similaridades e diferenças entre ele e os indivíduos com os quais interage, possibilitando a percepção das determinações históricas que forjam os grupos, a partir dos aspectos determinantes de produção material da vida. Por isto, como defende Lane (1984), a consciência de classe é uma categoria sociológica ${ }^{3}$, na medida em que a consciência de sié uma categoria psicológica.

Para a autora, a consciência do indivíduo pode ser apreendida no plano da ação, isto é, a partir de sua capacidade de alterar as relações sociais nas quais está inserido de maneira ao atendimento de suas necessidades e resolução das contradições identificadas.

O pensar uma ação pode simplesmente reproduzir essa ideologia, na medida em que se submete ou a reproduz através de explicações do tipo 'é assim que deve ser, é assim que se faz’. Porém, o pensar uma ação pode ser um confronte das possíveis consequências tanto imediatas como mediatas. Este pensar recupera

3 Enquanto categoria sociológica, as discussões sobre consciência demandam necessariamente conceitos sobre alienação. Sobre esta questão José D'Assunção Barros, em sua produção "O conceito de alienação no jovem Marx", sustenta que: "Marx ocupara-se essencialmente do problema da alienação humana nas suas diversas formas (inclusive no trabalho, mas também na religião, na política, nas próprias relações ecológicas do homem com a natureza). Ao mesmo tempo, seu viés era mais filosófico, seus interesses mais abrangentes, sua tonalidade mais intensamente humanista. Ao entrar em contato intelectual com o livro A situação da classe trabalhadora na Inglaterra (1845), Marx perceberia, ou julgaria perceber (conforme se dê ou não crédito à sua escolha ou descoberta), que a alienação produzida no mundo do trabalho era o ventre materno de todas as alienações - a raiz do estranhamento que lançava no sofrimento e na inconsciência o homem comum do mundo moderno". 
experiências anteriores, quando ações transformaram o ambiente e outras, omitidas, mantiveram o status quo, apesar de ter havido uma necessidade que gerou a contradição entre fazer/não fazer. Refletir sobre estas contradições e suas consequências fará com que a ação decorrente seja um avanço no processo de conscientização. Se esta reflexão não ocorre, o pensar a ação se caracterizará por uma resposta pronta, tida como 'verdadeira', já elaborada pelo grupo, reproduzindo a ideologia e mantendo o indivíduo alienado. (LANE, 1984, p. 43, grifos nossos).

Destarte, aquele indivíduo pode ser considerado consciente, quando por meio da reflexão aplicada à sua dinâmica social, identifica conteúdos contraditórios em suas ações, por meio da não correspondência com os interesses finalísticos, seus e do seu grupo, podendo a partir destas constatações operar modificações nas atividades realizadas, a partir de um agir dirigido à mudança. Ou, pode ainda implementar uma manutenção das ações vazias de sentido, por meio de impossibilidade de reflexão/ação, restando alienado em relação ao produto de suas ações e, como consequência, em relação a elaboração de si mesmo.

0 sujeito alienado encontra-se incapaz de operar reflexões em suas ações e a partir delas necessárias modificações, mantendo-se como produto de ações já pensadas, elaboradas fora de seu campo de consciência, atribuindo, em razão desta dinâmica cognitiva, a condição de dado natural a processos sociais, isto é, processos socialmente constituídos são percebidos pelo indivíduo como dados naturais, sobre os quais pensa não possuir capacidade de transformação, esvaziando assim seu protagonismo na elaboração das condições materiais da vida e, em consequência, na elaboração de si mesmo.

Neste intervalo, a liberdade de consciência deve ser compreendida enquanto experiência de consciência em oposição à alienação. Ao passo que a ausência de liberdade de consciência corresponde à ausência de consciência, sendo esta ausência, em si mesma, um estado de alienação. Logo, o indivíduo alienado em relação à sua condição e atuação social, à historicidade intrínseca aos processos constitutivos que o atravessam e o determinam, não goza de consciência e, portanto, não há que se falar em liberdade, sem que se afirme a superação do estágios de alienação e uma assunção de protagonismo irrenunciável nos processos de autoelaboração.

\subsubsection{IGUALDADE ENTRE OS CIDADÃOS}

A discussão sobre a igualdade entre os cidadãos demanda uma elucidação previa do conteúdo a ser operacionalizado para o conceito de condição cidadã. Henri Pena-Ruiz (2003b, p. 14), entende a cidadania como: "a afirmação da distinção entre o homem particulare a pessoa pública, o cidadão", (Sendo tal condição percebida não como uma) "peculiaridade cultural, mas uma conquista do espírito de liberdade: nenhuma civilização segregou (estas duas condições) espontaneamente".

Ao negar uma espontaneidade para a condição cidadã, Pena-Ruiz (2003b) defenda a perspectiva de que naturalmente os indivíduos não terão uma inclinação para o convívio público, sendo portanto, necessário que se desenvolva tal aptidão artificialmente, como uma habilidade para o transito no espaço público. Desta forma, o homem particular é marcado pela autodeterminação, elaborado a partir do estado de consciência experimentado pelo indivíduo, enquanto que a persona pública se manifesta na medida em que o indivíduo reconhece o outro como detentor dos mesmos direitos à liberdade de consciência, consequente autodeterminação e demais direitos que dela se desdobram elaborados a partir da alteridade.

Neste sentido, a faceta pública da cidadania é a condição pela qual o indivíduo se encontra apto para o convívio em sociedade, determinado pelo reconhecimento de que o outro é igual possuidor do direito de definir-se e redefinir-se na medida de seus interesses e que, o espaço público existe para viabilizar a pluralidade e a autodeterminação. Nisto, a dimensão coletiva do homem público é elaborada a partir das demandas que o convívio requer, nas questões que a dinâmica democrática por si mesma vem a exigir, sendo, v.g., as convicções religiosas conteúdos reservados ao espaço privado da consciência e não ao espaço comum. 
O cidadão é portanto marcado pela faceta privada na medida em que se é demandada a possibilidade de autorreflexão e autodeterminação, como reflexos invariáveis do exercício de consciência de si, a saber, do gozo da liberdade de consciência. Mas é, concomitantemente marcado pela faceta pública, por meio da alteridade, quando chamado a manifestar o reconhecimento do outro como titular das mesmas condições.

Sobre a experiência dos sentidos de cidadania, Luis Alberto Warat (2010, p. 108), considera que:

A cidadania termina sendo um termo central no direito político da modernidade, não obstante a pós-modernidade conseguiu esvaziá-lo de sentido. Em nome da cidadania hoje se pode dizer qualquer coisa; se transformou em um lugar comum, vazio de sentido e valores. A cidadania substancialmente tem a ver com a construção do eu próprio e a afirmação do seu valor (grifos nossos).

\section{Por isso:}

Reconstruir a cidadania (em termos de emergência e experiência de sentidos, em cenários modernos/pós-modernos de alienação, implica) superar um vazio de sentido que faz da cidadania os resíduos humanos exige uma carga expressa contra os encontros velozes que substituem os vínculos e uma memória geográfica esvaziada de objetos, são idos ou lugares de recordação. A cidadania é, sobretudo, uma estratégia de preservação do território. (WARAT, 2010, p. 109).

Neste intervalo, quando são evocados termos como 'encontros velozes', 'memória geográfica esvaziada de objetos' e 'preservação de território', estar-se-ia enfrentando a questão da ausência de consciência de si e social, num contexto de afirmação e preservação identitária, e, sobretudo numa afirmação da cidadania enquanto realização jurídico-social, como manifestação identitária. Isto porque, pode vir a ser a cidadania, seu exercício, um território de elaboração e expressão de um eu para si e para o outro, um espaço a partir da alteridade, mas antes dela, um campo de preservação. Assim, aquele indivíduo que se encontra em um estado de alienação, incapaz de articular os aspectos sociais que atravessam sua ela- boração identitária, não se encontra suficiente apto a afirmar-se e agir como cidadão, nem em sua perspectiva privada, muito menos em sua faceta pública.

Destaque-se que, embora percebida a cidadania como fenômeno não-espontâneo, seus sentidos jamais poderiam ser dados verticalmente, aos indivíduos.Antes disto, devem por eles ser elaborados, pois, quando autênticos, estão intrincados na experiência social, manifestos por meio da consciência e da afirmação.

Assim, uma sociedade democrática é laica na medida em que nela existem cidadãos marcados pela autodeterminação (homem privado) e alteridade (persona pública) e estes, ao se encontrarem no gozo das mesmas prerrogativas, experimentam condições de equiparação de direitos e possibilidades.

\subsubsection{NEUTRALIDADE ESTATAL E A BUSCA DO BEM COMUM}

Nas palavras de Pena-Ruiz (2003b, p. 71), "a laicidade refere-se à unidade do povo [...], uma vez que é baseada em três elementos indissociáveis: [...] o interesse geral do bem comum a todos, como uma das razões para o estado". Este interesse, a busca pela promoção do bem comum a todos, é, como pontua o autor, a possibilidade de elaboração do espaço público, isto é, a superação da usurpação do espaço público como se privado fosse; configurando-se a laicidade, enquanto recurso neutro, como a possibilidade de "superação, na esfera pública, de qualquer poder ou influência exercida em nome de uma religião ou ideologia privada".

Precisamente acerca da emergência deste espaço comum, o filósofo francês destaca:

A esfera pública não é construída pela adição e justaposição de coletivos, mas por uma produção original de universalidade, concretamente constituída pelo interesse comum a todos, e fonte, por sua própria ordem, de abertura para um horizonte mais curto de Limitações inerentes a diferentes particularidades. (PENA-RUIZ, 2003b, p. 194).

Nesta mesma direção, Zuber (2010) pontua que "o Estado laico é um Estado neutro entre os cultos, independente de todos os cleros, afastado de qualquer con- 
cepção teológica”. A neutralidade laica, como aponta Cesar Ranquetat Jr., é mais que uma perspectiva de inercia estatal, possui, com efeito, uma dualidade semântica dirigida, tanto omissa quanto comissivamente:

Esta neutralidade apresenta dois sentidos diferentes, o primeiro já destacado acima: exclusão da religião do Estado e da esfera pública. Pode-se falar, então, de neutralidade-exclusão. 0 segundo sentido refere-se à imparcialidade do Estado com respeito às religiões, o que resulta na necessidade do Estado em tratar com igualdade as religiões. Trata-se neste caso da neutralidade-imparcialidade. (RANQUETAT JR., 2008, p. 5, grifos nossos).

Quando percebida a neutralidade como modalidade de exclusão no espaço e poder público da manipulação e influencia de interesses eminentemente privados, e também como modalidade de imparcialidade, uma vez que se posiciona em equidistância em relação à todos os credos e culturas, assume o elemento neutro da laicidade uma condição essencial ao exercício dos dois pressupostos anteriores. Deste modo, somente será laica, quando materialmente neutra, a saber, apta a veicular conteúdos que sejam de interesse comum e por todos acessível. Isto é o que coloca Yves Charles Zarka (2013, p. 80) ao discutir este aspecto das sociedades modernas:

A neutralidade do Estado tinha, de fato, como correlato a existência de um espaço civil que fosse teológica ou religiosamente indiferente e suscetivel de aceitar a coexistência de religiões diferentes. A sociedade civil, onde se tecem as relações econômicas, sociais, profissionais, afetivas e morais, não é ela mesma determinada religiosamente, podendo, então, se constituir em espaço no qual uma pluralidade de religiões pode se inscrever [...] a terceira consideração toca a relação entre neutralidade do Estado e laicidade. Muitas vezes temos a tendência de fazer a laicidade uma doutrina filosófica completa da política, como se o conjunto da organização político-jurídico do Estado de direito pudesse se deduzir da noção de laicidade. Em verdade, a laicidade do espaço público e, em particular, da educação, esta que é primordial por ser responsável, por sua vez, pela formação do ser humano e pela instituição do cidadão, é uma consequência da neutralidade do Estado. Foi a partir do momento em que o Estado se encontrou desonerado de qualquer função espiritual concernente ao sagrado que a ideia de laicidade pôde ganhar espaço. (Grifos nossos).
Como sustenta Zarka (2013), a sociedade que não está determinada religiosamente, isto é, por uma perspectiva privada especifica, pode constituir um espaço onde a pluralidade pode ser experimentada, não podendo tal neutralidade laica ser concebida como uma condição apriorística do Estado, pelo contrário, apenas pode atingir tal condição quando o estado se exercer as modalidades de neutralidade-exclusão e neutralidade-imparcialidade. Neste intervalo, faz-se possível, a formação do ser humano para a condição cidadã e experiência de consciência.

Deve então ser neutra a esfera pública, para não ser reduzida a um instrumento do interesse privado, e, por isso, excludente; e quando excludente, totalitária, por esvaziar os sentidos plurais, tornando-se alienante e antidemocrática. A laicidade estrita, segundo Pena -Ruiz (2003b), demanda uma neutralidade estatal que entenda como inadmissível o uso, em qualquer nível, de recursos religiosos - ou mesmo culturais quando estes forem nitidamente privados e não nacionais, não de uma cultura nacional -, como recurso de legitimação política ou como finalidade de política pública.

Tais usos poriam em risco a ideia de igualdade entre os cidadãos, quando veiculado o conteúdo privado com status de coisa pública, encontra-se sob risco o exercício da liberdade de consciência e sua livre experienciação. Daí uma rígida separação, compreendida como neutralidade que exige do Estado o uso de conteúdos que sejam, notadamente, do interesse geral, que a todos privilegie e por todos sejam desejados, sem qualquer excepcionalidade.

\section{AGIR COMUNICATIVO, LAICIDADE PRAGMÁTICA COMO TERRITÓRIO DE ELABORAÇÃO COLETIVA E CIDADANIA CRÍTICA}

Na assertiva de Gustin e Dias (2013, p. 14), é preciso que se compreenda como objeto de estudo da ciência jurídica "o fenômeno jurídico historicamente realizado. Um fenômeno que se positiva no espaço e no tempo e que se realiza como experiência efetiva”. Neste senti- 
do, num cenário teórico pós-positivista, em que se mira a efetividade ${ }^{4}$ das instituições jurídicas, não se pode conceber uma ciência do direito que não esteja aportada em um campo de experiência social.

$E$, neste diapasão, o objeto do Direito passa a se estruturar a partir de um novo modelo: o paradigma da razão comunicacional.

Para explicação dessa nova racionalidade, há que se compreender que os seres humanos, convivem com uma tensão permanente em razão de sua dupla natureza, ao mesmo tempo individual e social. Há que se entender, igualmente, que esses seres, na atualidade, inserem-se em uma ordem social imersa em uma contradição fundamental. Enquanto o ser humano estrutura sua individualidade moral a partir de relações de fidelidade com as esferas locais e com os grupos menores e mais próximos (familiares, profissionais, de amigos, entre outros), as fronteiras nacionais, empresas de grande porte, grupos associativos e representação profissional, etc) passam a conviver em um ambiente cosmopolita, de expansão não só de fronteiras geográficas, mas, inclusive, dos limites éticos, políticos e jurídicos, numa expansão também permanente de suas necessidades. (GUSTIN; DIAS, 2013, p.15, grifos nossos).

Aquilo tratado pelas autoras como dupla nature$z a$, é, com efeito, a condição essencial para o cidadão, a saber, sua manifestação privada, identitária, e sua elaboração pública, a persona que se desenvolve em razão do outro, com o qual continuamente entra em contato: a alteridade. A permanente tensão, precisa-

4 Ao abordar a questão da efetividade, Barroso (2015, p.518) assevera que: "para realizar seus propósitos, o movimento pela efetividade promoveu, com sucesso, três mudanças de paradigma na teoria e na prática do direito constitucional no País. No plano jurídico, atribuiu normatividade plena à Constituição, que se tornou fonte de direitos e de obrigações, independentemente de intermediação do legislador. Do ponto de vista cientificoou dogmático, reconheceu ao direito constitucional um objeto próprio e autônomo, estremando-o do discurso puramente político ou sociológico. E, por fim, sob o aspecto institucional, contribuiu para a ascensão do Poder Judiciário no Brasil, dando-lhe um papel mais destacado na concretização dos valores e dos direitos constitucionais. O discurso normativo, científico e judicialista foi fruto de uma necessidade histórica. O positivismo constitucional, que deu impulso ao movimento, não importava em reduzir o direito à norma, mas sim em elevá-lo a esta condição, pois até então ele havia sido menos do que norma. A efetividade foi o rito de passagem do velho para o novo direito constitucional, fazendo com que a Constituição deixasse de ser uma miragem, com as honras de uma falsa supremacia, que não se traduzia em proveito para a cidadania". mente inserida no discurso, faz menção à condição do diferente, inerente ao pluralismo, na constatação que deriva da identidade que o outro, ao ser diferente, não se confunde com o eu, que se busca afirmar epreservar, logo, um ensejo a circunstancias de tensão e conflito. Por isto, deve o Direito, buscar meios suficientes, para a promoção da autonomia, indispensável à promoção da faceta privada da cidadania, ao tempo em que, também, fomenta a alteridade quando da elaboração da persona pública nos indivíduos.

É neste cenário complexo que o paradigma da razão comunicacional pode oferecer os suportes teóricos necessários à instrumentalização de tais assertivas.

Simone Goyard-Fabre (2006, p. 277), discorrendo sobre a perspectiva teórica elaborada por Jürgen Habermas, assevera:

J. Habermas é fascinado pelo vigor filosófico e pelo alcance epistemológico do pensamento da Aufklärung. Esse vivo interesse é acompanhado pelo sentimento de que a modernidade do século XVIII é portadora de um projeto cujo inacabamento é mui especialmente nefasto para a esfera prática. Por isso Habermas chega a almejar reconstruir o materialismo histórico cujas fissuras e lacunas são pro ele percebidas como o indício das fraquezas e das insuficiências que ele contém. À medida que se firma seu desígnio, ele o completa e, logo, o suplanta pela vontade de reelaborar um anova teoria crítica suscetível de revisar o marxismo em suas próprias raízes. É a esse projeto que corresponde, em 1981, a Theorie des kommunikativen Handelns (Teoria do agir comunicativo).

Segundo Habermas (1990, p. 276), o núcleo propositivo de sua teoria, diz respeito à alteração na dinâmica entre os sujeitos e aqueles saberes indispensáveis para sua articulação social, de maneira que, para ele: "o paradigma do conhecimento de objetos tem de ser substituído pelo paradigma da compreensão mútua entre sujeitos capazes de falar e agir". Para tanto, seria preciso inaugurar uma nova forma de pensar e operacionalizar a racionalidade:

A razão reduzida à capacidade subjetiva de entendimento e de actividade teleológica corresponde à imagem de uma razão exclusiva que, quanto mais aspira triunfalmente às alturas se desenraiza até finalmente 
cair, vítima da força da sua oculta origem heterogênea [...] o trabalho de desconstrução, por mais entusiasta que seja, só pode ter consequências definíveis quando o paradigma da consciência de si, da auto-referencia de um sujeito que conhece e age isoladamente é substituído por outro, pelo paradigma da intercompreensão, isto é, da relação intersubjetiva dos indivíduos, que socializados através da comunicação, se reconhecem mutuamente. (HABERMAS, 1990, p. 284-288).

\section{E continua:}

\begin{abstract}
Essa racionalidade comunicativa exprime-se na força unificadora da fala orientada ao entendimento mútuo, discurso que assegura aos falantes envolvidos um mundo da vida intersubjetivamente partilhado e, ao mesmo tempo, o horizonte no interior do qual todos podem se referir a um único e mesmo mundo objetivo. (HABERMAS, 2004, p. 107, grifos nossos).
\end{abstract}

Para Habermas (2004, p. 292), “a razão comunicacional, apesar de seu caráter puramente processual, aliviado de todas as hipotecas religiosas ou metafísicas, está diretamente implicada no processo de vida social". Assim, enquanto teoria procedimental, o agir comunicativo se instrumentaliza por meio de elementos que se elaboram por meio da linguagem, naquilo tratado pelo autor como atos de fala:

Os atos elementares de fala apresentam uma estrutura na qual se combinam três elementos: a componente proposicional para a representação (ou menção) de estados de coisas, a componente elocutória para a admissão de relações interpessoais e, finalmente, as componentes linguísticas que experimentam a intenção de quem fala. (HABERMAS, 1990, p. 289).

A razão comunicacional, figura então como instrumento de elaboração deliberativa da sociedade, quando sustenta um papel protagonista para todos os indivíduos que se encontrem em sociedade, não havendo que se reconhecer legitimidade jurídica ou social, sem que se constatem tais dinâmicas, como pontuam Miracy B. S. Gustin e Maria T. F. Dias (2013, p. 17-18):

A razão comunicativa ou comunicacional é aquela que promove a inclusão de um sujeito emancipado que se insere socialmente por meio de múltiplas formas de parti- cipação nas esferas públicas e privadas de tomada de decisão. Ele é um sujeito complexo e múltiplo. De um lado, ele é a soma de interesses e de papeis diversificados, muitas vezes dicotômicos: pai/filho, trabalhador/patrão, professor/aluno, cidadão, entre outros que se diversificam em termos de habilidades, qualificações, capacidades e responsabilidades. São múltiplas suas relações discursivas: grupos diferentes de pessoas interagem com sua identidade heterogênea. Finalmente, esse ser complexo comunica-se por meio de mais de uma linguagem moral, ou seja, ele estrutura sua individualidade por intermédio de valores e princípios diversificados.

Nisto, emerge um conceito de cidadania para além da afirmação dupla, dicotômica entre a persona privada e pública que deve manifestar socialmente o sujeito, mas uma mais complexa, aquela apta a inferir juízos sobre sua própria condição; uma cidadania crítica. Sendo o cidadão crítico, aquele que se autopercebe para além de um constructo jurídico, da assertiva inerte no discurso jurídico, mas como condição essencial e mensurável no campo de realização da vida social. Uma cidadania, que se autoelabore, na interface entre a afirmação identitária e a alteridade, que opere sobre seu próprio eixo as inferências necessárias ao alargamento.

Neste interim, a busca pela efetividade da laicidade, a saber, pela experiência de uma estrita laicidade, sobretudo quando pensada a partir da persecução dos seus pressupostos, pode assegurar elementos que são prévios e necessários ao agir comunicativo, como a consciência e igualdade, indispensáveis aos componentes proposicional, elocutória e linguística, que integram os atos de fala do agir comunicativo. Isto, com efeito, em muito se aproxima de uma perspectiva pragmática para laicidade, tendo em vista que:

\begin{abstract}
Um indivíduo pragmático é aquele que não se prende de antemão a princípios ideológicos ou fundamentações metafísicas, mas sim lida com as questões tendo em vista suas conseqüências práticas. Essas duas definições, conquanto não sejam mutuamente excludentes, acabam informando duas visões diferentes de filosofia: uma mais normativa e outra mais utilitária. (KINOUCHI, 2007, p. 215).
\end{abstract}

Uma laicidade que se pretenda efetiva, cujos pressupostos são experimentados socialmente é, a um só 
tempo, normativa e utilitária, logo, pragmática; quando se dirige à realização da vida, permanecendo em seu núcleo teórico, permanentemente, próxima de uma perspectiva comunicacional, na medida em que jamais se poderia restar elaborada sem a interação de todos os indivíduos socialmente interessados. De outro modo, não haveria de ser considerada como laicidade.

Finalmente, para que se afirme uma cidadania crítica, construída por meio de uma racionalidade comunicacional, faz-se imprescindível a experiência laica, determinada não apenas pela formalidade dos textos normativos, mas antes, mensurável a partir dos três pressupostos da laicidade, histórica e socialmente realizados.

\section{CONSIDERAÇÕES FINAIS}

As discussões foram disparadas com a explanação sobre os limites da atuação hermenêutica pós-positivista, seguindo-se da exposição dos elementos interdisciplinares para a teoria da laicidade estrita, sustentada por pensadores franceses, neste estudo representado pro Henri Pena-Ruiz. Finalmente, articulou-se o delineamento desta laicidade pragmática com o conceito de cidadania crítica, pensada esta última a partir da perspectiva teórica habermasiana.

Ao considerar os elementos agrupados nesta produção, a partir do diálogo entre os discursos: jurídico, psicológico e sociológico, foi possível inferir a importância da elaboração de laicidade pragmática, em uma perspectiva interdisciplinar, tanto em razão da qualidade essencialmente complexa do fenômeno laico, quanto pelas demandas intrínsecas ao paradigma hermenêutico pós-positivista, que se dirige a uma concretude das diretrizes normativas aportando sua legitimidade na correspondência com a realidade social.

Neste sentido, afirmar a laicidade como uma mera previsão normativa de separação, sem que se discutam os efeitos e premissas desta separação e sua indissociável relação com a elaboração da atuação dos indivíduos, seria negar ao ideal laico sua potencialidade de realizar-se, ao insulá-lo nas abstrações jurídicas. Por esta razão, deve-se considerar os pressupostos da lai- cidade estrita, quais sejam: liberdade de consciência, igualdade entre cidadãos críticos e neutralidade do Estado, como instrumento viabilizador para a materialidade de diversos direitos que se encontram amparados pela garantia constitucional, uma inflexão necessária à práxis hermenêutica nacional.

Finalmente, é pertinente que se considere o caráter não exauriente desta produção, que a seu turno, dedicou-se a propor discussões sobre a matéria sem contudo pretender esgotar a questão. Sendo imprescindível a realização de pesquisas outras, dedicadas não apenas ao alargamento teórico da laicidade estrita, como também a realização de estudos empíricos dirigidos à mensuração do fenômeno e dos impactos da aplicação da teoria na realidade social.

\section{REFERENCIAL}

BARROS, José D’Assunção. O conceito de alienação no jovem Marx. Tempo Social, revista de sociologia da USP, v.23, n.1, p.223-245, jun. 2011. Disponível em: <http://www.scielo.br/pdf/ts/v23n1/v23n1a11.pdf>.

\section{BARROSO, Luis Roberto. Curso de direito}

constitucional contemporâneo: os conceitos fundamentais e a construção do novo modelo. 5.ed. São Paulo: Saraiva, 2015.

\section{BLANCARTE. Roberto. O porquê de um Estado} Laico. In: Roberto Arriada Lorea (Org.). Em defesa das liberdades laicas. Porto Alegre: Livraria do Advogado, 2008.

\section{CATROGA, Fernando. Entre deuses e Césares:}

secularização, laicidade e religião civil, uma perspectiva histórica. 2.ed. Coimbra: Almedina, 2010.

\section{GOYARD-FABRE, Simone. Filosofia crítica e razão}

jurídica. Tradução de Maria Ermantina de Almeida Prado Galvão; revisão da tradução por Márcia Valéria Martinez de Aguiar. São Paulo: Martins Fontes, 2006. GUSTIN, Miracy B.S.; DIAS, Maria Tereza Fonseca. (Re) 
pensando a pesquisa jurídica: teoria e prática. 4.ed Revisada e Atualizada. Belo Horizonte: Del Rey, 2013.

\section{HABERMAS, Jürgen. 0 discurso filosófico da}

modernidade. Trad. Ana Maria Bernardo et al. Lisboa: Dom Quixote, 1990.

HABERMAS, Jürgen. Verdade e justificação: ensaios filosóficos. Trad. Milton Camargo Mota. São Paulo: Loyola, 2004.

KINOUCHI, Renato Rodrigues. Notas introdutórias ao pragmatismo clássico. scientiæzudia, São Paulo, v.5, n.2, p.215-26, 2007. Disponivel em: <http://www.scielo. br/pdf/ss/v5n2/a04v5n2.pdf>. Acesso em: set 2017.

LANE, Silvia Tatiana Maurer; CODO, Wanderley (Org.). Psicologia social: o homem em movimento. São Paulo: Brasiliense, 1984.

LANE, Silvia Tatiana Maurer. Consciência, alienação: a ideologia no nível individual. In: LANE, Silvia T. M.; CODO, Wanderley (Org.). Psicologia social: o homem em movimento. São Paulo: Brasiliense, 1984.

\section{LEONTIEV, Alexis Nikolaievich. 0 desenvolvimento} do psiquismo. Tradução de Rubens Eduardo Frias. 2.ed. São Paulo: Centauro, 2004.

LOREA, Roberto Arriada et al. Em defesa das liberdades laicas. Porto Alegre: Livraria do Advogado, 2008.

ORO, Ari Pedro. A laicidade na América Latina: uma apreciação antropológica. In: Roberto Arriada Lorea (Org.). Em defesa das liberdades laicas. Porto Alegre: Livraria do Advogado, 2008.
PENA-RUIZ, Henri. Dieu et Marianne. Philosophie de lalaïcité. Paris: PUF, 1999.

PENA-RUIZ, Henri. La laïcité. Paris: Garnier-

Flammarion, 2003a.

PENA-RUIZ, Henri. Qu'est-ce que lalaïcité? Paris: Gallimard, 2003b.

RANQUETAT JUNIOR, C.A. Laicidade, laicismo e secularização: definindo e esclarecendo conceitos. Revista Sociais e Humanas, v.21, n.1, 2008. Disponível em: <https://periodicos.ufsm.br/ sociaisehumanas/article/view/773>. Acesso em: set 2017.

SARMENTO, Dabiel. O crucifixo nos Tribunais e a laicidade do Estado. In: LOREA, Roberto Arriada (Org.). Em defesa das liberdades laicas. Porto Alegre: Livraria do Advogado, 2008.

UNDURRAGA, Gabriel Álvarez. Metodologia de lalnvestigación Jurídica: hacia una nueva perspectiva. Santiago: Universidad Central de Chile, 2002.

WARAT, Luis Alberto. A rua grita Dionósio!: Direitos humanos da alteridade, surrealismo e cartografia. Tradução e organização: Vívian Alves de Assis, Julio Cesar Marcelino Jr. e Alexandre Morais da Rosa. Rio de janeiro: Lumen Juris, 2010.

ZUBER, Valentine. La laïcitérépublicaineen France ou lesparadoxes d'unprocessushistorique de laïcisation (XVIIle-XXIesiècles). In: Ler História: 2010. Disponível em: <https://lerhistoria.revues. org/1370\#quotation>. Acesso em: set 2017. 
Data da submissão: 19 de outubro de 2017

Avaliado em: 10 de novembro de 2017 (Avaliador A)

Avaliado em: 22 de dezembro de 2017 (Avaliador B)

Aceito em: 26 de dezembro de 2017
1 Professor Universitário e Advogado, Mestrando em Psicologia Social pelo Programa de Pós-Graduação em Psicologia da Universidade Federal do Vale do São Francisco (UNIVASF), Pós-graduado em Gestão Pública pela Faculdade de Ciências Aplicadas e Sociais de Petrolina (FACAPE) e em Direito Constitucional Aplicado pela Damásio Educacional. E-mail: phablo-freire@hotmail.com

2 Acadêmico de Direito pela Faculdade de Ciências Aplicadas e Sociais de Petrolina (FACAPE). E-mail: ramonreis03@hotmail.com 